\title{
Effect of hydrogen addition in diesel/natural gas dual-fuel combustion with late injection
}

\author{
Antonio Caricato ${ }^{1}$, Antonio Paolo Carlucci ${ }^{1,{ }^{*}}$, Antonio Ficarella ${ }^{1}$, and Luciano Strafella ${ }^{1}$ \\ ${ }^{1}$ Department of Engineering for Innovation, University of Salento, Lecce, 73100, Italy
}

\begin{abstract}
In a previous work, the effectiveness of late pilot injection on improving combustion behaviour - in terms of fuel conversion efficiency and pollutant emission levels - in a diesel/natural gas dual-fuel engine was assessed. Then, an additional set of experiments was performed, aiming at speeding up the combustion process possibly without penalizing $\mathrm{NO}_{\mathrm{x}}$ levels. Therefore, hydrogen was added to natural gas in a percentage equal to $10 \%$. Results show that hydrogen addition has a significant effect on the combustion development specially during the early stage of combustion: ignition delay is shortened and combustion centre is advanced, while the combustion duration increases when pilot injection timing is set to conventional values, while remains basically unchanged for late timings. Fuel conversion efficiency is only slightly penalized when hydrogen is added. Moreover, it was confirmed that, in general, combustion strategy with late pilot injection timing does not penalize fuel conversion efficiency; indeed, in some cases, it actually increases. Concerning regulated emission levels, it is again proven that late pilot injection does not penalize pollutant production: the hydrocarbons and carbon monoxide reduce as pilot injection is delayed, probably due to the higher temperatures reached into the cylinder during most part of the expansion stroke. Moreover, adding hydrogen always reduces their levels. Concerning $\mathrm{NO}_{x}$, they are drastically reduced delaying pilot injection; as expected, hydrogen addition promotes $\mathrm{NO}_{\mathrm{x}}$ formation, but the increase, evident with conventional pilot injection timings, becomes marginal with late injection strategy. Therefore, combustion strategy performance with late pilot injection in dual-fuel diesel/natural gas combustion conditions can be further improved with $10 \%$ hydrogen addition to natural gas.
\end{abstract}

\section{Introduction}

The continuous increase in energy demand is in contrast with the rapid depletion of crude oil around the world. Therefore, it is mandatory to promote the utilization of alternative fuels on large scale specially for mobility. Besides biofuels, still limited in commercial availability, natural gas (NG), on the other hand, is widely accepted, thanks to its lowered environmental impact and the possibility to easily convert existing engines to be fed with Compressed Natural Gas (CNG) [1]. On the other hand, new combustion strategies are

\footnotetext{
*Corresponding author: paolo.carlucci@unisalento.it
} 
being proposed and tested with the aim of improving fuel conversion efficiency and reduce pollutants production. Homogeneous charge compression ignition (HCCI) concept is put into practice with different strategies involving injection phasing and pressure, exhaust gas recirculation, combination of two or more fuels with different reactivity [2], etc... In a previous work, the Authors showed that retarding pilot injection helps in obtaining a reduction of pollutant emission levels while keeping unchanged or with only little penalty on engine fuel conversion efficiency of a dual-fuel diesel/natural gas engine [3]. In these conditions, a critical point was shown to be the combustion velocity, because the fuel burns entirely during the expansion stroke. Therefore, in order to speeding up the combustion process, in this work hydrogen was added to natural gas in a percentage equal to $10 \%$. Previous works, in fact, have shown that hydrogen addition to $\mathrm{CNG}$ leads to rapid formation of $\mathrm{OH}-$ and $\mathrm{H}+$ radicals, which improve burning speed of $\mathrm{CNG}$ - in which, as well known, the rate of heat release is lower if compared with only diesel conditions - by enhancing the reaction rates [1,4]. Moreover, low fraction of hydrogen in methane can suppress the uncontrolled combustion of hydrogen [5].

During tests, the combustion behaviour of dual-fuel diesel/natural gas was characterized; in particular, the effect of adding $10 \%$ of hydrogen in mixture with natural gas was evaluated. Tests were performed using "conventional" as well as "late" pilot injection timings. Moreover, the effect of increasing pilot injection pressure was also evaluated, performing the tests at two pilot injection pressures, namely 500 and $1500 \mathrm{bar}$.

\section{Experimental setup}

All the tests were conducted in "Combustion and Spray" laboratory at the University of Salento. The laboratory is equipped with a single-cylinder, 4-stroke, common rail diesel research engine (AVL model 5402). Thanks to the experimental setup and the characteristic of the engine control, the effect of hydrogen additivation on diesel/natural gas combustion has been evaluated, with conventional and late Start Of pilot Injection (SOI) and two different levels of pilot Injection Pressures (IP). The technical features of the engine are listed in Table 1, while in Fig. 1 the scheme of the experimental layout is reported. The engine is equipped with a high pressure "common rail" injection system; the solenoid injectors are characterized by 5 holes with a diameter of $170 \mu \mathrm{m}$ each.

The control unit is the BOSCH model EDC15-C7, through which it is possible to: modify the quantity of injected diesel fuel, IP, SOI, etc... During the tests, SOI and IP were varied. Tested values are reported in Table 2: in particular, SOI is expressed in Crank Angle Degrees After Top Dead Center (CADATDC). The pilot fuel quantity, the engine speed and the indicated mean effective pressure were kept constant for all tests and equal to 6 $\mathrm{mm} 3 /$ cycle, $1500 \mathrm{rpm}$ and $0,5 \mathrm{MPa}$ respectively.

The crankshaft is coupled to an engine dynamometer, which is part of the AVL EMCOM 300 test bench; in this way it was possible to set the speed and the load of the engine.

The gas injector used for inducting gas fuel in Dual-Fuel (DF) mode is placed at a distance of $400 \mathrm{~mm}$ from the intake valves. The gases taken from the cylinders are first mixed in the desired quantities through a mixer and then stored in a pressurized tank at the desired pressure, ready for feeding the engine. The scheme of this mixing system is described in more detail in [6]. During the experimental campaign, it was decided to inject either Compressed Natural Gas (CNG) or a mixture of $10 \%$ hydrogen and $90 \% \mathrm{CNG}$ (HCNG). Therefore, the gaseous flow has been fumigated along the intake duct of the engine by means of an injector consisting of an automatic poppet valve, with contrast spring, actuated by the natural gas itself introduced by a solenoid valve injector (Magneti Marelli 0529/A $03755 \mathrm{~F}$ IHP 072 gasoline 6 holes injector, $0.15 \mathrm{~mm}$ diameter) in a small accumulation volume. More details about the fumigation system are reported in [7]. The management and 
control of gas injection was performed through a Sourcing Digital Output NI 9474 module connected to a specific LabVIEW file. In detail, it is possible to vary the gas flow rate using a PWM signal by setting the duty cycle and the opening frequency of the injector.

Table 1. - Engine technical specifications

\begin{tabular}{ll}
\hline Specification & Nominal value/description \\
\hline Maximum Power & $18 \mathrm{~kW}$ \\
Bore & $85 \mathrm{~mm}$ \\
Stroke & $90 \mathrm{~mm}$ \\
Original Compression ratio & $17.1: 1$ \\
Combustion chamber & Bowl with valve pockets and flat head \\
Injection system & Common Rail \\
Max Injection pressure & 1600 bar \\
Valve timing & Opening \\
Intake & $13.5^{\circ} \mathrm{BTDC} \quad 46.5^{\circ} \mathrm{ABDC}$ \\
Exhaust & $51.5^{\circ} \mathrm{BBDC} \quad 16.5^{\circ} \mathrm{ATDC}$ \\
\hline
\end{tabular}

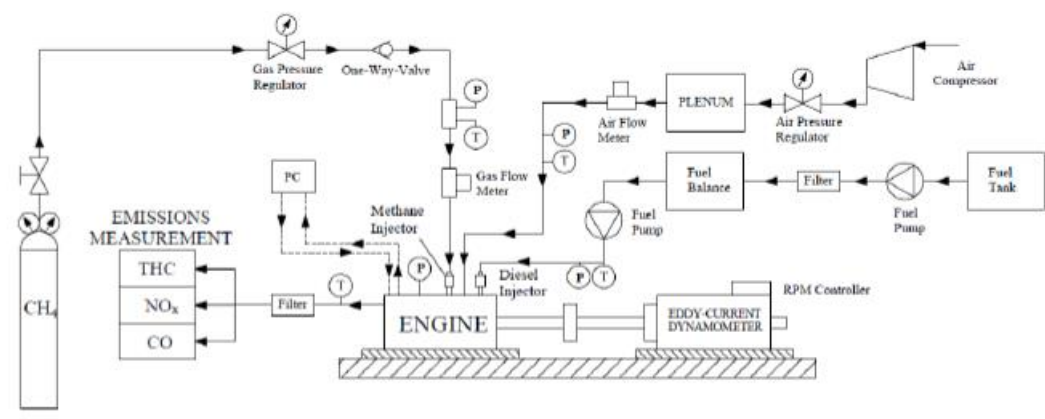

Fig. 1. Experimental setup

Table 2. Engine settings during the experimental campaign

\begin{tabular}{|l|l|c|}
\hline \multirow{4}{*}{$\mathrm{IP}=500 \mathrm{bar}$} & SOI $=-25 \mathrm{CADATDC}$ & $\mathrm{CNG}$ or $\mathrm{HCNG}$ \\
\cline { 2 - 3 } & SOI $=-2,5$ CADATDC & $\mathrm{CNG}$ or $\mathrm{HCNG}$ \\
\cline { 2 - 3 } & $\mathrm{SOI}=-0$ CADATDC & $\mathrm{CNG}$ or $\mathrm{HCNG}$ \\
\hline $\mathrm{IP}=1500 \mathrm{bar}$ & $\mathrm{SOI}=-15 \mathrm{CADATDC}$ & $\mathrm{CNG}$ or $\mathrm{HCNG}$ \\
\cline { 2 - 3 } & SOI $=-2,5$ CADATDC & $\mathrm{CNG}$ or $\mathrm{HCNG}$ \\
\cline { 2 - 3 } & SOI $=-0$ CADATDC & HCNG \\
\hline
\end{tabular}

As previously said, during the tests, the injector was positioned at about $400 \mathrm{~mm}$ from the cylinder axis, so that a homogeneous gaseous fuel-air mixture was obtained before trapping it into the cylinder. Although the engine is provided with a swirl and tumble valves, the 
mixture was introduced in the cylinder through the swirl valve only. This solution was chosen because it provided the best compromise in terms of engine performance and emission levels [8]. This solution was implemented by using a metal closure blade placed in front of the tumble intake valve.

During tests, data acquisition was started only after steady conditions were reached. An AVL piezoelectric pressure sensor model QC33C was mounted in the combustion chamber. The signal sampling was triggered and synchronized with TDC by an AVL encoder model 364C, with a resolution of 0.2 Crank Angle Degrees (CAD). To obtain the absolute cylinder pressure, $\left(p_{c y l, a b s}\right)$ a pegging routine was implemented, through which the pressure measured by the in-cylinder sensor during the intake stroke was imposed equal to the average pressure measured by an absolute pressure sensor (Kistler piezo resistive sensor type 4045A2) mounted along the intake duct. Then, the absolute cylinder pressure so obtained was stored for 20 consecutive cycles, averaged and then post-processed. The gross Heat Release Rate (HRR) was then calculated as:

$$
H R R=\frac{d Q_{n e t}}{d(C A D)}+\frac{d Q_{w}}{d(C A D)}
$$

The term $d Q n e t / d(C A D)$ was estimated based on the single zone simplified model:

$$
\frac{d Q_{n e t}}{d(C A D)}=\frac{k}{k-1} p_{c y l, a b s}(C A D) \frac{d V(C A D)}{d(C A D)}+\frac{1}{k-1} V(C A D) \frac{d p_{c y l, a b s}(C A D)}{d(C A D)}
$$

where $k$ is the ratio of specific heats (assumed equal to 1.38) and $V(C A D)$ is the cylinder volume variable with $\mathrm{CAD}$. The term $d Q_{w} / d(C A D)$, accounting for the heat transfer through the cylinder walls, has been estimated as:

$$
\frac{d Q_{w}}{d(C A D)}=A_{h t} h_{c}\left(T-T_{w}\right)
$$

where $A_{h t}$ is the instantaneous cylinder heat exchange surface (crown of cylinder head, cylinder walls and piston head), $T$ is the instantaneous cylinder average temperature, $T_{w}$ is the average temperature of the inner cylinder surface while the total heat transfer coefficient $h_{c}$ was estimated as proposed by Woschni. Based on $p_{c y l, a b s}$, it was possible to estimate the indicated power $P_{i}$ supplied by the engine:

$$
P_{i}=\frac{n}{n_{R}} \oint_{c y c l e} p_{c y l, a b s} d V
$$

where $n$ is the engine speed while $n_{R}(=2$ in this case) is the number of crank revolutions for each power stroke. The average diesel fuel consumption was measured by means of an AVL 733S Fuel Balance. The gaseous fuel flux was stabilized by means of a $0.8 \mathrm{~L}$ plenum positioned upstream the natural gas injector. The average gaseous fuel consumption $G_{g a s}$ was measured by means of a thermal mass flow Aalborg Instruments and Controls Inc., model DFC 36. The measurement of the fuels consumption allowed to estimate the fuel conversion efficiency referred to the indicated power, $\eta_{f}$ : 


$$
\eta_{f}=\frac{P_{i}}{\dot{m}_{d} H_{i, d}+G_{g a s} H_{i, g a s}}
$$

where $H_{i, d}$ and $H_{i, g a s}$ are the lower calorific value respectively of diesel and gaseous fuels. The last part of the acquisition chain is the exhaust gas analyzer, which allows reading the emissions concentration in the desired sampling sections. The exhaust gas analyzer is the AVL AMA i60, able to measure several species present in the exhaust gas flow: Carbon Monoxide $(\mathrm{CO})$, Unburned Hydrocarbons $(\mathrm{HC})$ and Nitrogen Oxides $\left(N \mathrm{O}_{x}\right)$. AVL AMA i60 uses nondispersive IR measurements to detect $\mathrm{CO}$, chemiluminescence to detect $\mathrm{NO}_{\mathrm{x}}$ and a flame ionization detector to detect HC. Particulate matter at the tailpipe was not measured since, as known, the utilization of natural gas and hydrogen drastically reduces this pollutant.

\section{Results and discussion}

In Fig. 2, left column, the in-cylinder pressure and related HRR are compared when DF combustion with CNG or HCNG (in both cases ignited by neat diesel pilot injection) is realized. Tests were performed varying pilot injection timing on three levels: 25CADATDC (case a), representing conventional timing), -2,5 and 0 CADATDC (cases b) and c), representing late pilot injection timing). Pilot injection pressure was kept constantly equal to 500bar. With conventional timing, combustion starts before TDC, while with late timings, combustion starts after TDC, i.e. during the expansion stroke. Introducing HCNG instead of CNG as low reactivity fuel leads to advanced ignition and higher in-cylinder pressure and, consequently, HRR during the early phase of combustion. The HRR shows a very high peak and a premixed-like shape with conventional pilot injection timing, while with late timings, the peak si significantly reduced and the early combustion phase is followed by a diffusive-like HRR.

In order to highlight the effect of pilot injection pressure, a second set of tests was performed, during which pilot injection pressure was arisen to 1500bar. In Fig. 2, right column, the in-cylinder pressure and related HRR are compared when DF with CNG or HCNG (in both cases ignited by neat diesel pilot injection) is realized. The first thing that can be observed is that the first tested pilot injection timing was -15CADATDC (case a), representing conventional timing), differently from the -25 tested at 500bar. This was due to the fact that misfire and/or poor and unstable combustion was observed at 25CADATDC. Moreover, tests at $-2,5$ and 0 CADATDC (cases b) and c), representing late pilot injection timing) were also performed. It shall be emphasized, however, that the test at 0 CADATDC using CNG as low reactivity fuel determined misfire and/or poor and unstable combustion. Therefore, related data are not reported.

With a pilot injection pressure equal to $1500 \mathrm{bar}$, a combustion behaviour similar to what observed to 500bar can be confirmed. In particular, with conventional timing, combustion starts before TDC, while with late timings, combustion starts after TDC, i.e. during the expansion stroke. Again, introducing $\mathrm{HCNG}$ instead of CNG as low reactivity fuel leads to advanced ignition and higher in-cylinder pressure and, consequently, HRR during the early phase of combustion. The HRR shows, in this case too, a very high peak and a premixedlike shape with conventional pilot injection timing, while with late timings, the peak si significantly reduced and the early combustion phase is followed by a diffusive-like HRR. However, with 1500 bar, in-cylinder and HRR peaks are lower than those observed with 500bar. 


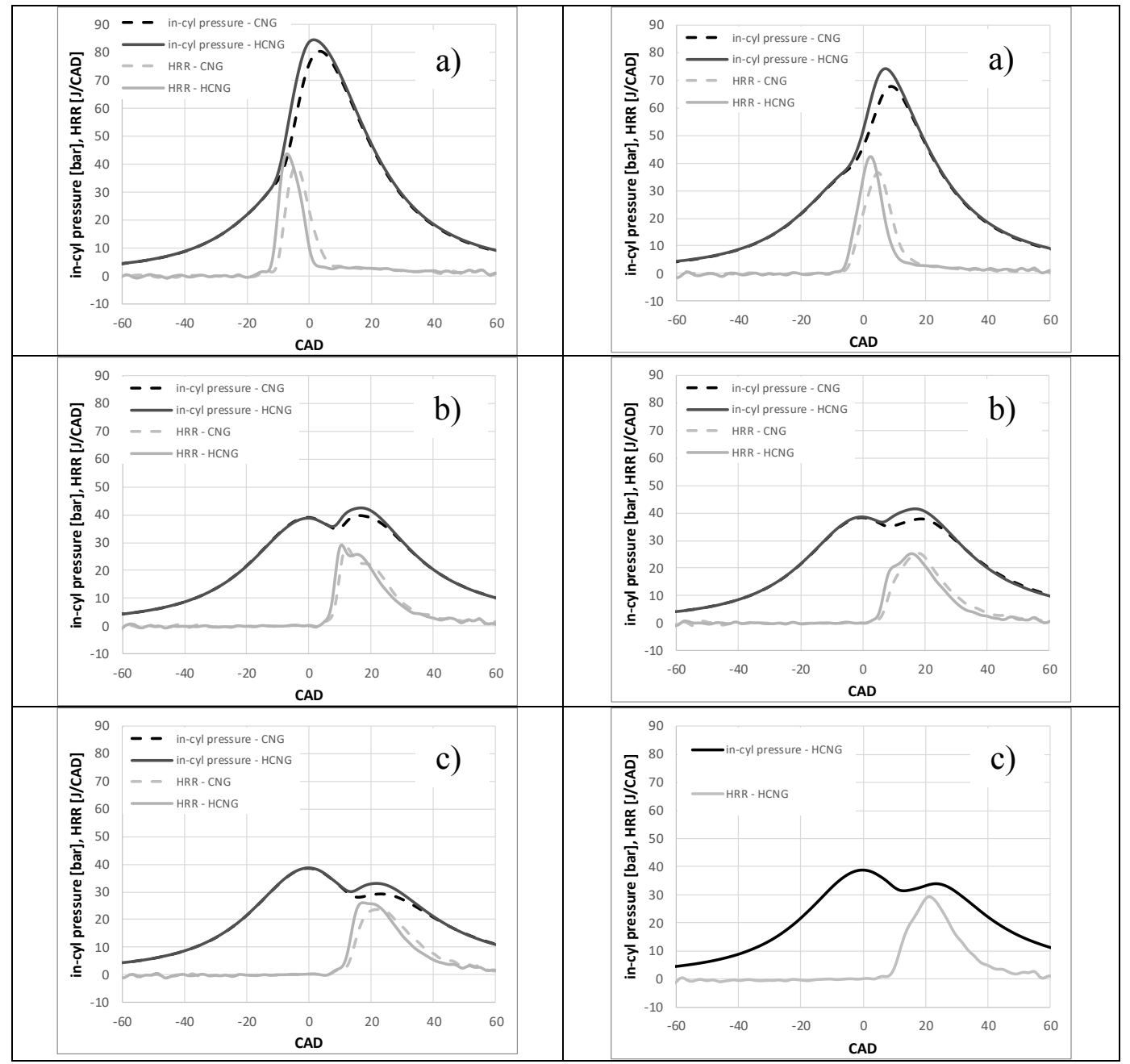

Fig. 2. In-cylinder pressure and HRR comparison with CNG or HCNG DF combustion varying SOI. Left column: $\mathrm{IP}=500 \mathrm{bar}$; right column: $\mathrm{IP}=1500 \mathrm{bar}$

In Fig. 3 the Ignition Delay (ID) - defined as the angular difference between the CA at which $5 \%$ of heat has been released and the CA beginning of the energizing current - for all tests is reported. As well known, pilot injection timing significantly affects ID. In fact, for both pilot injection pressures (left and right plots) it can be observed that, as well documented in literature, ID shows a decreasing-increasing behaviour as injection timing is retarded. This is due to the fact that, with injection performed far from TDC (either advanced or retarded), the in-cylinder pressure and temperature are less favourable to promote chemical and physical preignition phenomena. From Fig. 3 it can be also noticed that the utilization of HCNG as low reactivity fuel always leads to a reduction of ID. This is confirmed by data already published in open literature $[1,4,5]$. 


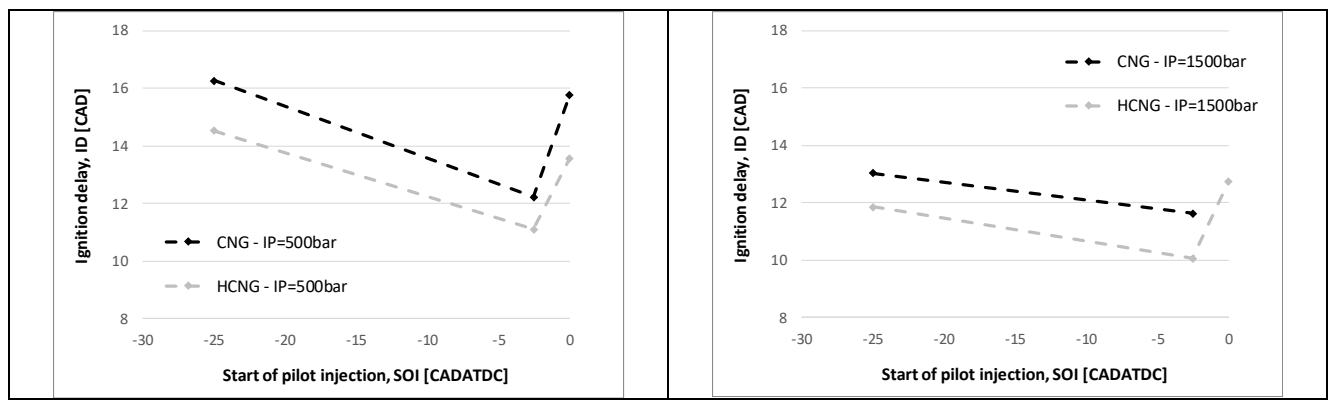

Fig. 3. Ignition delay with $\mathrm{CNG}$ or $\mathrm{HCNG}$ DF combustion SOI. Left column: $\mathrm{IP}=500$ bar; right column: IP=1500bar.

In Fig. 4 the combustion center, i.e. the CA at which $50 \%$ of heat has been released, is shown. The combustion center delays as pilot injection timing is delayed, for both pilot injection pressures (left and right plots). In general, the utilization of HCNG as low reactivity fuel always leads to an advance of CA50, as a consequence of advanced ignition of fuel mixture.

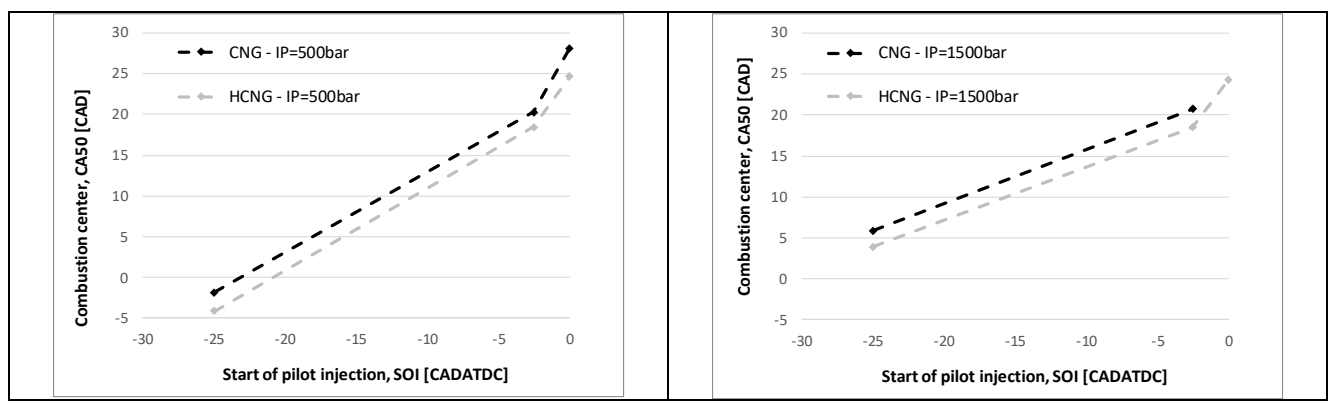

Fig. 4. Combustion center with $\mathrm{CNG}$ or HCNG DF combustion varying SOI. Left column: $\mathrm{IP}=500 \mathrm{bar}$; right column: $\mathrm{IP}=1500 \mathrm{bar}$.

Finally, in Fig. 5 the combustion duration (CD) is reported, defined as the interval between the two CAs at which $90 \%$ and $10 \%$ of heat has been released. It can be noticed that the longest $\mathrm{CD}$ are observed for conventional pilot injection timings. As far as pilot injection timing is delayed, combustion duration is shortened. This trend is very important, given that a combustion triggered by a late pilot injection will have less time to get complete. Moreover, the combustion is faster (lower CD) as pilot injection pressure is increased (right plots). From Fig. 5 it can be also observed that using HCNG as low reactivity fuel leads to a longer combustion. This is evident from HRR curves in Fig. 2; in fact, using HCNG, combustion starts earlier but ends more or less in the same way characterizing combustion with CNG. This result is in line with the findings reported in [11], in which it is underlined that adding hydrogen mainly affects the initial and middle stages of combustion, while it has little effect on the late combustion stage. 


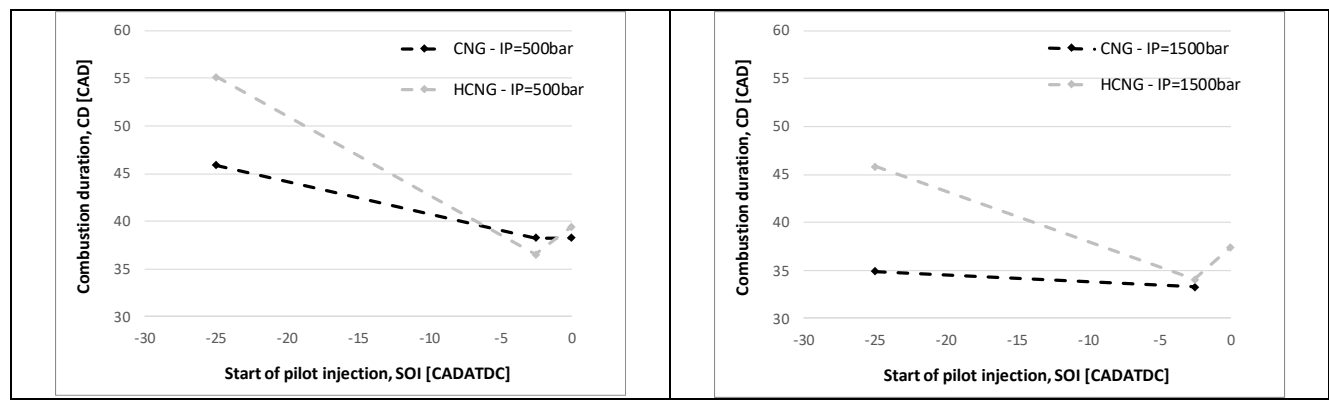

Fig. 5. Combustion duration with CNG or HCNG DF combustion varying SOI. Left column: $\mathrm{IP}=500 \mathrm{bar}$; right column: $\mathrm{IP}=1500 \mathrm{bar}$.

The combustion development, which results in the above in-cylinder pressure and HRR histories, determines the conversion efficiency of heat into useful work. In Fig. 6, the fuel conversion efficiency referred to the indicated power is shown. The results show a slightly increasing trend with $\mathrm{CNG}$ and a slightly decreasing trend with $\mathrm{HCNG}$ as pilot injection timing is delayed. In general, using CNG leads to higher values of fuel conversion efficiency. This behaviour, observed with IP equal to 500bar, changes increasing it up to 1500 bar. In any case, with high pilot injection pressure, the higher fuel conversion efficiency is observed with CNG.

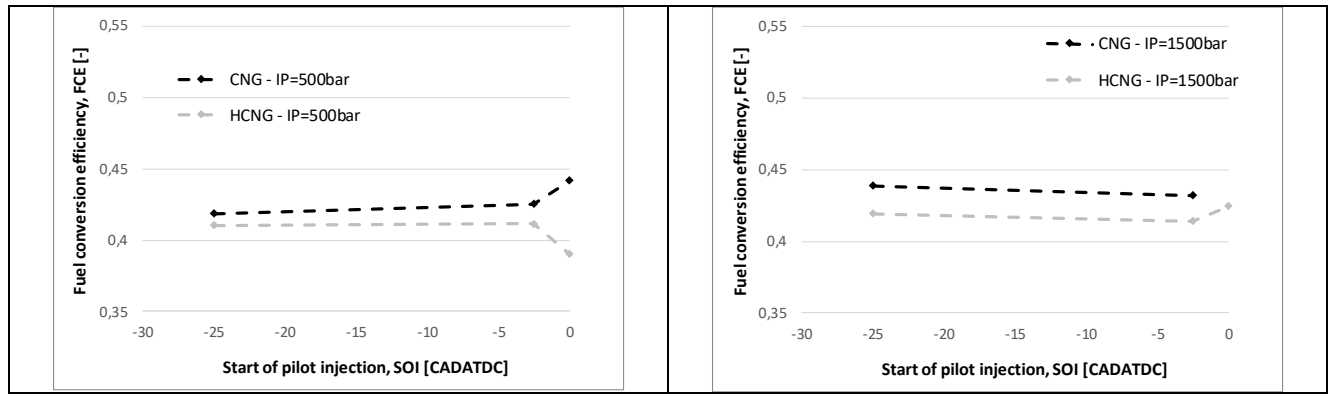

Fig. 6. Fuel conversion efficiency referred to the indicated power with CNG or HCNG DF combustion varying SOI. Left column: $\mathrm{IP}=500 \mathrm{bar}$; right column: $\mathrm{IP}=1500 \mathrm{bar}$.

The combustion development determines also the regulated pollutant emission levels at the exhaust. Before analyzing the emission levels, it is useful to show the behaviour of incylinder bulk temperature as a function of CAD for the different engine settings. In Fig. 7 it is possible to observe that, with delayed SOI, the peak temperature is reduced. However, starting from about 30 CADATDC and for all the duration of the expansion stroke, the temperature remains higher than that reached with conventional SOI. Increasing IP determines a reduction of the peak temperature with conventional SOI, and an increase with late pilot injection. However, during expansion stroke, the temperature reduces to less than $800 \mathrm{~K}$, while, with lower IP, remains always higher than $800 \mathrm{~K}$. Although species formation depends on local conditions into the chamber, yet the behaviour of bulk temperature can provide some useful information for interpreting the main mechanisms determining pollutant levels at the exhaust. 


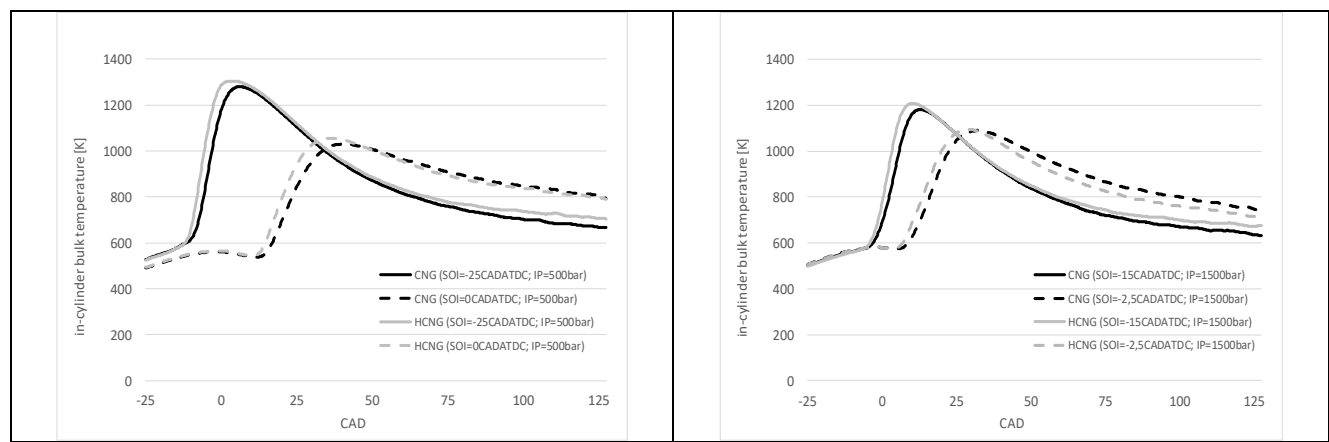

Fig. 7. In-cylinder bulk temperature comparison with CNG or HCNG DF combustion varying SOI. Left column: $\mathrm{IP}=500 \mathrm{bar}$; right column: $\mathrm{IP}=1500 \mathrm{bar}$.

Concerning ISHC, in Fig. 8 the levels are shown. Delaying pilot injection timing reduces $\mathrm{HC}$ levels, probably due to the higher temperatures realized into the cylinder during most of the expansion stroke. Moreover, the utilization of CNG leads always to levels higher than those observed with HCNG, for all values of SOI and IP; with HCNG, the reached temperatures are always slightly higher than those observed with CNG. Finally, it can be observed that pilot injection pressure impacts less on ISHC levels, probably because the opposite trend shown by peak and queue temperature, respectively decreasing and increasing with increasing IP, tend to balance each other.

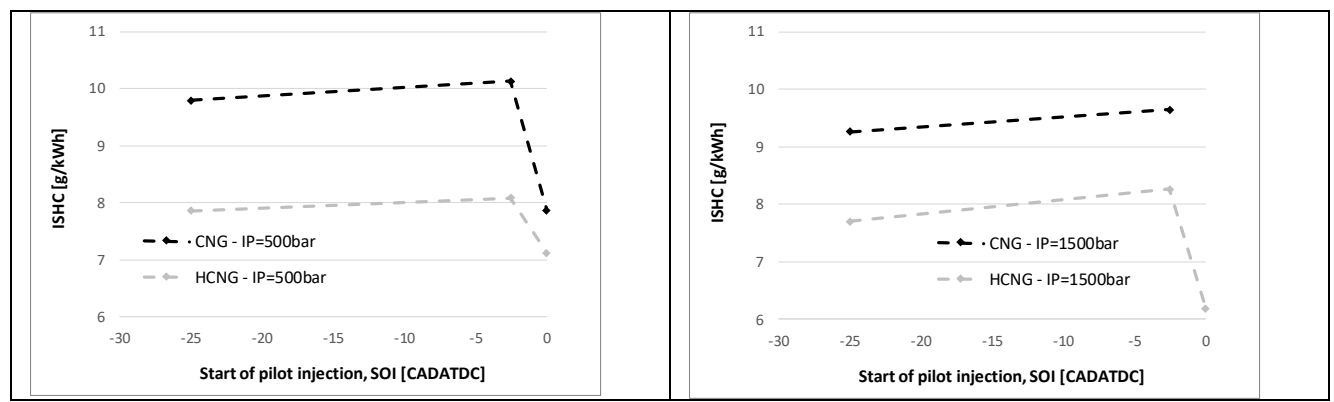

Fig. 8. ISHC with $\mathrm{CNG}$ or $\mathrm{HCNG} \mathrm{DF}$ combustion varying SOI. Left column: $\mathrm{IP}=500 \mathrm{bar}$; right column: $\mathrm{IP}=1500 \mathrm{bar}$.

Concerning ISCO, in Fig. 9 the specific levels are plotted. The trend is increasing and then decreasing when retarding pilot injection timing, more evident at low pilot injection pressure. Moreover, almost always the utilization of HCNG leads to reduced specific CO levels. 


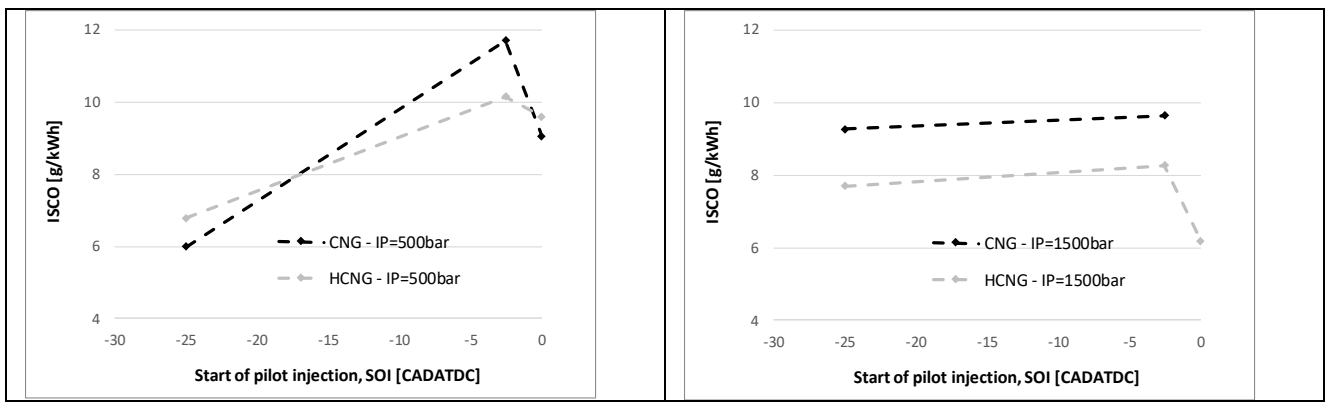

Fig. 9. ISCO with $\mathrm{CNG}$ or HCNG DF combustion varying SOI. Left column: IP=500bar; right column: IP=1500bar.

Concerning $\mathrm{ISNO}_{\mathrm{x}}$, in Fig. 10 the levels are shown. As expected, the utilization of HCNG leads always to levels higher than those observed with $\mathrm{CNG}$, for all values of pilot injection timing and pressure, due primarily to higher temperatures reached into the cylinder when $\mathrm{HCNG}$ is used. However, the difference is more pronounced for conventional pilot injections, while is very low for late pilot injections. More interesting, delaying pilot injection timing leads to a significant abatement of specific $\mathrm{NO}_{\mathrm{x}}$ emission levels, because, despite in these conditions the temperature during most of the expansion stroke is higher, the reached temperature values are not sufficient for activating $\mathrm{NO}_{\mathrm{x}}$ formation mechanism. This behaviour is observed at both pilot injection pressures, but it shall be also emphasized that, increasing pilot injection pressure leads to an overall significant reduction of emission levels.

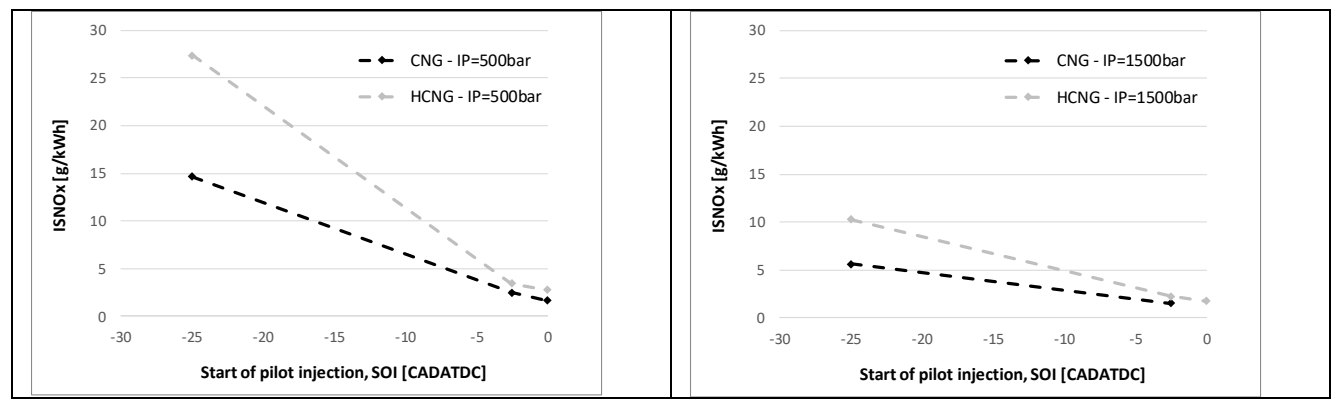

Fig. 10. $\mathrm{ISNO}_{\mathrm{x}}$ with $\mathrm{CNG}$ or $\mathrm{HCNG} \mathrm{DF}$ combustion varying SOI. Left column: IP=500bar; right column: IP=1500bar.

\section{Conclusions}

In this work, a set of experiments has been performed, aiming at speeding up the combustion process realized in an single cylinder reciprocating engine in dual-fuel diesel/natural gas conditions, in which the combustion of the low reactivity fuel is triggered by a diesel pilot injection whose timing is phased across TDC, i.e. later compared to conventional calibration strategies. From the results provided by the measurements, the following main findings can be driven:

-hydrogen addition has a significant effect on the combustion development specially during the early stage of combustion: ignition delay is shortened and combustion center is advanced, while the combustion duration increases when pilot injection 
timing is set to conventional values, while remains basically unchanged for late timings;

-fuel conversion efficiency is only slightly penalized when HCNG is used. Moreover, it was confirmed that, in general, combustion strategy with late pilot injection timing does not penalize fuel conversion efficiency; indeed, in some cases, it actually increases;

- $\mathrm{HC}$ and $\mathrm{CO}$ at the exhaust reduce as pilot injection is delayed, probably due to the higher temperatures reached into the cylinder during most part of the expansion stroke. Moreover, adding hydrogen has always a beneficial effect on these pollutant levels;

-concerning $\mathrm{NO}_{x}$, they are drastically reduced delaying pilot injection; as expected, hydrogen addition promote $\mathrm{NO}_{\mathrm{x}}$ formation, but the increase, evident with conventional pilot injection timings, becomes marginal with late injection strategy.

Overall, it can be stated that combustion strategy performance with late pilot injection in dual-fuel diesel/natural gas combustion conditions can be further improved with $10 \%$ hydrogen addition to natural gas as low reactivity fuels.

\section{References}

1. T.S. Hora, A.K. Agarwal, Fuel 160 470-478 (2015).

2. A.P. Carlucci, A. Ficarella, D. Laforgia, J Energ Eng 141 C4014006 (2015).

3. A.P. Carlucci, A. Ficarella, D. Laforgia and L. Strafella, Energy, Environment, and Sustainability 267-296 (2019).

4. C.F. Lee, Y. Pang, H. Wu, J.J. Hernández, S. Zhang, F. Liu, Fuel, 280118639 (2020).

5. J.H. Zhou, C.S. Cheung, C.W. Leung, Int. J. Hydrog. Energy 39 4611-4621 (2014).

6. A.P. Carlucci, A. Ficarella, D. Laforgia, J Energ Eng 140 A4014011 (2014).

7. A.P. Carlucci, A. de Risi, D. Laforgia, F. Naccarato, Energy 33 256-263 (2008).

8. A.P. Carlucci, D. Laforgia, R. Saracino, SAE Technical Paper 2009-01-0949. 